Check for updates

Cite this: Sustainable Energy Fuels, 2019, 3, 292

Received 9th August 2018

Accepted 24th November 2018

DOI: $10.1039 / \mathrm{c} 8 \mathrm{se} 00408 \mathrm{k}$

rsc.li/sustainable-energy

\title{
A synergistic use of microalgae and macroalgae for heavy metal bioremediation and bioenergy production through hydrothermal liquefaction $\uparrow$
}

Marco Piccini, (D) ${ }^{a}$ Sofia Raikova, ${ }^{a}$ Michael J. Allen (D) ${ }^{c d}$ and Christopher J. Chuck (D)*b

In this investigation a novel synergistic approach for the bioremediation of metal-contaminated water and bioenergy production was developed. Two microalgae, Chlorella vulgaris and Arthrospira platensis (Spirulina), and two macroalgae, Ulva lactuca and Sargassum muticum, were used as passive bioremediation agents for the metals $\mathrm{Ni}(॥), \mathrm{Zn}(॥), \mathrm{Cd}(॥)$ and $\mathrm{Cu}(॥)$. The metals were added singularly and in combination between 10-150 mM. The metal contaminated biomass was then processed through hydrothermal liquefaction to yield four phases: a bio-crude oil, an aqueous phase, solid residue and gas. Both C. vulgaris and A. platensis gave high bio-crude yields of 39 and 31 wt\% respectively, while $U$. lactuca and S. muticum gave $14 \%$ and $9 \%$ respectively. Initial studies demonstrated that the addition of up to $150 \mathrm{mM}$ of the target metal sulfates to the biomass feedstock did not significantly affect bio-crude production, and, for microalgae, over $99 \%$ of the target metals were partitioned to the solid phase products predominantly as phosphates or oxides. Subsequently, bioremediation of waste water and HTL were successfully coupled, with over $80 \%$ of a $10 \mathrm{mM}$ solution of the metals biosorbed, though efficacy depended heavily on the algal species. Upon HTL of the remediating biomass, the yield and composition of the bio-crude were not changed significantly. For the microalgae, the aqueous phase contained significant nitrogen, potassium and phosphate levels, and the majority of the target metals deposited in the solid phase, with over $99.5 \%$ metal recovery for Spirulina when all four metals were used. The macroalgal species were not as effective in this process, with limited phosphate recovery in the aqueous phase (albeit with extensive potassium recovery) and with less than $50 \%$ of the target metals depositing in the solid residue for the Ulva species examined, presumably due to the affinity of the metals to proteinous species rather than polysaccharide in this species. Combining microalgal bioremediation with hydrothermal liquefaction is therefore a potentially highly effective method of remediating contaminated waste waters, whilst a macroalgae based process may offer a cheaper alternative, albeit with substantially reduced efficacy. The recovery of the target metals and multiple product formation improves the economic viability of the process, thereby valorising the bioremediation process and subsidising environmental clean-up.

\section{Introduction}

One promising route to advanced biofuel production from sustainable biomass is the hydrothermal liquefaction of microand macroalgae. Algal biomass can be grown on non-arable land or in a marine environment (where they can also be

${ }^{a}$ Centre for Doctoral Training in Sustainable Chemical Technologies, Department of Chemical Engineering, University of Bath, Claverton Down, Bath, UK, BA2 7AY

${ }^{b}$ Department of Chemical Engineering, University of Bath, Claverton Down, Bath, UK, BA2 7AY. E-mail: c.chuck@bath.ac.uk

${ }^{c}$ College of Life and Environmental Sciences, University of Exeter, Streatham Campus, Exeter, Devon, UK, EX4 4QD

${ }^{d}$ Plymouth Marine Laboratory, Prospect Place, The Hoe, Plymouth, UK, PL1 3DH

$\dagger$ Electronic supplementary information (ESI) available. See DOI: $10.1039 / \mathrm{c} 8 \mathrm{se} 00408 \mathrm{k}$ harvested opportunistically), and couple fast growth with high photosynthetic efficiency. The resulting wet biomass can be thermally processed directly at between $5-20 \%$ solid loading under subcritical conditions (typically $300-350{ }^{\circ} \mathrm{C}, \quad 150-$ 200 bar). In the process, biomass undergoes a complex series of reactions, ultimately leading to the formation of a bio-crude oil. ${ }^{1}$ The other phases produced by HTL processing are: a gas phase, mainly composed of $\mathrm{CO}_{2}$; an aqueous phase, in which are dissolved light organic and inorganic compounds; and a solid residue. ${ }^{2}$

Recent technoeconomic analysis has demonstrated the suitability of HTL as a production process for fuels, in particular when the nutrients within the system can be recycled from the aqueous phase, and algal growth can be coupled with a service function such as waste water remediation. ${ }^{3}$ To this end, a number of studies have demonstrated the suitability of 
remediating municipal waste water on the pilot scale and the subsequent processing of the algal biomass via HTL, removing $\mathrm{N}$ and $\mathrm{P}$ from the water using microalgae, and subsequently partitioning them to the aqueous phase of the HTL products. ${ }^{4-7}$ From these studies, it is suggested that an energy recovery of approximately $50 \%$ and an initial solid loading of over $14 \%$ would lead to an economically viable process. $^{8}$

Municipal waste waters generally contain high levels of $\mathrm{N}$ and $\mathrm{P}$, and are suitable for algal cultivation all year round. On the other hand, a more challenging area is the bioremediation of heavy metal-contaminated effluents. ${ }^{9}$ Industrial waste waters often contain heavy metals, and their removal is conventionally achieved through physicochemical processes, including chemical precipitation, ion exchange and adsorption; such processes tend to be expensive, produce no valorisable products and often are not completely effective. The remediation of heavy metal ions using micro- and macroalgae has been heavily researched, with reports on effective remediation from a huge range of micro- and macroalgae species, including species from the genera Chlorella, Arthrospira, Ulva and Sargassum..$^{\mathbf{1 0 - 1 2}}$ Generally microalga can achieve efficiencies of over 95\%, under optimal conditions though this necessitates a high biomass loading and extended contact time with the pollutant of hours. While this is generally slower than chemical precipitation, ${ }^{9}$ which also requires a lower loading, the additional biomass generated can be used for valorisation to reduce the costs of the initial remediation. Additional advantages are potentially lower operating costs, the high efficiency in remediating heavy metals that are present in far lower concentrations and less amount of spent biosorbent for final disposal that has no value. ${ }^{\mathbf{1 2}}$

Two distinct mechanisms have been investigated: active bioadsorption, where living algae are cultured on diluted solutions of the effluent; and passive, where dead algal biomass binds the metal cations through the hydroxyl, carboxyl, sulfhydryl, amino and phosphate groups present in the proteins, carbohydrates and lipids of the cell wall via ion exchange and complexation. ${ }^{13}$ The passive adsorption mechanism relies predominantly on the type and number of active sites present and is therefore highly dependent on the properties of the algae species (such as composition, size, surface area), but also on the metal ion (size, charge), together with many additional environmental factors.

Adsorption experiments are generally conducted on single metal species solutions in order to understand the influence of characteristic parameters. It has been demonstrated that, on increasing the initial metal concentration, the metal uptake increases, but the overall efficiency decreases. ${ }^{14,15}$ One of the most important parameters for metal uptake is $\mathrm{pH}$, as it influences functional group ionisation and complex formation constants. Metal bioadsorption is highly time-dependent: with live algae, the process is usually slow, and can take weeks for the algal biomass to adapt to the culture conditions and reach maximum biomass yield, whilst with dead biomass, it becomes much faster, typically occurring within tens of minutes. ${ }^{\mathbf{1 6 , 1 7}}$ Under optimised conditions, many algae strains have been shown to sequestrate up to tens (sometimes hundreds) of milligrams of metal per gram of biomass. ${ }^{\mathbf{1 0 1 1}}$ This elevated remediation potential has been gaining industrial interest, with some processes beginning to be commercialized. ${ }^{11,18}$ However, many challenges have yet to be faced, and producing an economic process will most likely rely heavily on appropriate biomass generation, supply and reuse, and metal recovery, as well as the valorisation of any products generated.

To this end, a number of studies have attempted to link bioremediation with bioenergy production. For example, Kim et al. demonstrated that an oleaginous algae, Nannochloropsis oculata, could actively remediate $\mathrm{Cr}$ from aqueous solutions while still producing reasonable levels of lipids for biodiesel production. ${ }^{19}$ Further studies have demonstrated this active approach, with high metal removal efficiencies of Zn, Mn, Cd, As and $\mathrm{Cu}$ being coupled successfully with lipid production..$^{\mathbf{2 0 - 2 4}}$ However, while these systems produce cleaner water, the problem of the metal contamination is transferred to the wet defatted biomass, which then requires extensive processing to be exploited in an appropriate manner.

Ideally, metals would partition to a minor fraction, which can be disposed of, recovered or reprocessed easily, with the majority of the carbon being transferred directly to the fuel product without fear of metal contamination. We recently reported on the active remediation of acid mine drainage with a mixed algal culture, which was then processed by hydrothermal liquefaction. ${ }^{25}$ The liquefaction demonstrated that large amounts of Fe had a positive effect on the crude yields, though other heavy metals present, such as $\mathrm{Sn}$ (II) and $\mathrm{Pb}$ (II), had little effect on the yield. Importantly, the heavy metals targeted were largely retained in the solid residue on liquefaction, offering a potential route to easy metal recovery and bioenergy production. This deposition of metals has also been observed in the liquefaction of swine manure ${ }^{\mathbf{2 6}}$ and naturally occuring algal blooms. $^{27}$

However, in the preliminary study, the active microalgal culture did not grow effectively within the toxic environment generated by the excessive metal contamination, and took a number of weeks to remediate the industrial effluent, emphasising the limitations of the active bioadsorption approach.

To address this, in this investigation we aimed to assess the suitability of HTL to process algal biomass used in the passive bioadsorption remediation of a heavy metal mixture, with two microalgal species (C. vulgaris and Spirulina) and two macroalgal species (U. lactuca and S. muticum). All four algae represent different remediation opportunities and applications with a global footprint: Chlorella and Spirulina are the most widely cultivated microalgae globally due to their fast and reliable growth properties (Chlorella, single cellular) and ability to withstand high $\mathrm{pH}$ (Spirulina, chain forming); while Ulva and Sargassum are ubiquitous green and brown macroalgae, respectively, often associated with problematic blooms following eutrophication of waters. The suitability of using HTL to produce a bio-crude oil, an aqueous phase where useful nutrients can be recovered from and a solid residue that would ideally contain the target metals was assessed. 


\section{Experimental}

\subsection{Materials}

Four of the most common metal pollutants in industrial waste waters are $\mathrm{Ni}(\mathrm{II}), \mathrm{Cu}(\mathrm{II}), \mathrm{Cd}(\mathrm{II})$ and $\mathrm{Zn}$ (II), ${ }^{28}$ and were used in this study as sulfate salts. Trace metal-grade $\mathrm{ZnSO}_{4} \cdot 7 \mathrm{H}_{2} \mathrm{O}, \mathrm{CuSO}_{4}$ $\cdot 5 \mathrm{H}_{2} \mathrm{O}, \mathrm{NiSO}_{4} \cdot 6 \mathrm{H}_{2} \mathrm{O}, \mathrm{CdSO}_{4} \cdot 8 / 3 \mathrm{H}_{2} \mathrm{O}, \mathrm{HNO}_{3} 70 \%$ were purchased from Sigma-Aldrich and used without further purification. Chlorella and Spirulina were obtained as food grade supplements from Naturya (Bath, UK) and used as supplied. Sargassum muticum and Ulva lactuca were collected according to previous studies, on $15^{\text {th }}$ May 2017, and oven-dried prior to use. ${ }^{29}$

\subsection{Methods}

Metal adsorption of the biomass was carried out according to literature precedent. ${ }^{11,12,30}$ In a typical procedure, $4 \mathrm{~g}$ of dry algal biomass and $100 \mathrm{~mL}$ of aqueous metal solution were placed in a conical flask, and the $\mathrm{pH}$ adjusted to the optimal values of 5.05.5 by the addition of $\mathrm{NaOH}$ or $\mathrm{H}_{2} \mathrm{SO}_{4}$. The flask was placed in an incubator with the temperature set to $20{ }^{\circ} \mathrm{C}$, and stirred at $200 \mathrm{rpm}$ for $2 \mathrm{~h}$; the $\mathrm{pH}$ was measured at the end. The mixture was then transferred into a $250 \mathrm{~mL}$ centrifuge bottle and centrifuged at $4000 \mathrm{rpm}$ for 15 minutes. From the supernatant, $80 \mathrm{~mL}$ was collected, while the remaining mixture (solid $+20 \mathrm{~mL}$ solution) was used in the next stage (hydrothermal liquefaction).

HTL was performed according to previously reported experiments. ${ }^{25}$ The mixture obtained after bioadsorption was transferred into a stainless steel reactor (approx. volume $50 \mathrm{~mL}$ ), equipped with a thermocouple, a pressure gauge and a pressure release valve. The reactor was sealed, then placed inside a vertical tubular furnace kept at $700{ }^{\circ} \mathrm{C}$ until the temperature inside the reactor reached $340{ }^{\circ} \mathrm{C}(\mathrm{ca} .12 \mathrm{~min})$, then removed and left to cool to ambient temperature (see ESI $\uparrow$ for a typical temperature profile). The gas phase volume was measured, the reactor was opened and the reactor contents filtered through a pre-weighted Fisher qualitative paper filter, allowing the aqueous phase to be collected. Once the filter was dry, the reactor and the filter were washed with chloroform until the solvent ran clear. The solvent was then removed using a rotary evaporator to recover the bio-crude. The filter was allowed to dry to recover the solid phase. The reactions without metals for the four species were done in triplicate to calculate the standard error. This is given in the ESI. $\dagger$

\subsection{Products characterization}

Elemental (CHN) analysis of algal feedstocks was carried out at London Metropolitan University. Ash content was determined by heating $0.5 \mathrm{~g}$ of algae in a muffle furnace at $550{ }^{\circ} \mathrm{C}$ for 5 hours and calculated by the weight difference. Higher heating values (HHV) were calculated from elemental composition according to the Channiwala \& Parikh equation: ${ }^{31}$

$\mathrm{HHV}=0.3491 \mathrm{C}+1.1783 \mathrm{H}+0.1005 \mathrm{~S}-0.1034 \mathrm{O}-0.0151 \mathrm{~N}-$ $0.0211 \mathrm{H}\left(\mathrm{MJ} \mathrm{kg}^{-1}\right)$
The supernatant phase obtained after bioadsorption and centrifugation was filtered through a $0.45 \mu \mathrm{m}$ syringe filter and diluted in deionized water. Metals content was analysed by Atomic Absorption Spectroscopy on a Perkin Elmer Analyst 100.

The different phases obtained after HTL were analysed as follows:

The bio-crude yield was calculated gravimetrically from the original weight of the biomass according to the following equation:

$$
\text { Oil yield }=\frac{\text { weight }_{\text {oil }} \times 100 \%}{\text { weight }_{\text {dry algae }}}
$$

The elemental composition ( $\mathrm{CHN}$ ) of the bio-crudes was analysed by OEA Laboratories Ltd, Callington, Cornwall, UK. (Oxygen content was calculated by difference.) The higher heating value (HHV) was calculated using the Channiwala \& Parikh equation, assuming negligible ash content. Metal and $\mathrm{P}$ analysis was analysed using ICP-OES. Samples were digested in $4 \mathrm{~mL}$ aqua regia at $95^{\circ} \mathrm{C}$ for 1 hour, then left to digest at ambient temperature for 24 hours before being made up to $20 \mathrm{~mL}$ with $10 \% \mathrm{NaOH}$ solution in deionised water to a $\mathrm{pH}$ of approx. 3 . The resulting solution was filtered through a $0.45 \mu \mathrm{m}$ filter membrane prior to analysis. ICP-OES was carried out externally by Yara U.K. Ltd. using an Agilent 700 series inductively coupled plasma optical emission spectrometer.

The aqueous phase was weighed and stored at $4{ }^{\circ} \mathrm{C}$ prior to analysis. The sample was sonicated in an ultrasonic bath in order to suspend the precipitated solids and make the mixture homogeneous. A sample of $200 \mu \mathrm{L}$ was taken, $\mathrm{HNO}_{3} 70 \%$ $(1.4 \mathrm{~mL})$ added to dissolve the solids, then the sample was made up to $20 \mathrm{~mL}$ with ultrapure water and its metal and $\mathrm{P}$ content analysed using ICP-MS at Greenpeace Laboratories, University of Exeter. For all samples out of the calibration range of the ICPMS, ICP-OES was used as given above (see ESI Table S1 $\dagger$ ). A $50 \mu \mathrm{L}$ aliquot of the original sample was diluted in $0.45 \mathrm{~mL}$ of $\mathrm{HCl} 36 \%$ and $9.5 \mathrm{~mL}$ of water; the sample was then analysed with a Shimadzu Total Organic Carbon Analyser, equipped with a TNM-L total nitrogen analyser unit, to determine its total nitrogen content.

The solid phase yield was calculated gravimetrically. Elemental (CHN) composition analysis was carried out at London Metropolitan University. The metal and $\mathrm{P}$ content was determined via ICP-MS (Greenpeace Laboratories, University of Exeter). Prior to being analysed, the solid was digested: to $35 \mathrm{mg}$ of solid in a PTFE vessel, $2 \mathrm{~mL}$ of $\mathrm{HNO}_{3} 70 \%$ was added. After $5 \mathrm{~min}, 2 \mathrm{~mL}$ of ultrapure water and $1 \mathrm{~mL}$ of $35 \% \mathrm{H}_{2} \mathrm{O}_{2}$ were added. The samples were then processed in a MARS5 Microwave Accelerated Reaction System at $480 \mathrm{~W}$, heated to $150{ }^{\circ} \mathrm{C}$ in $5 \mathrm{~min}$ and kept at $150{ }^{\circ} \mathrm{C}$ for $10 \mathrm{~min}$. After cooling, the samples were diluted with $5 \mathrm{~mL}$ of ultrapure water, filtered and then diluted $1: 200$ in $\mathrm{HNO}_{3} 5 \% \mathrm{v} / \mathrm{v}$ for ICP-MS analysis.

\section{Results and discussion}

Due to their abundance in the environment, these four metal species ( $\mathrm{Ni}, \mathrm{Cu}, \mathrm{Cd}, \mathrm{Zn}$ ) have been heavily reported in the 
literature as suitable for remediation through various algal bioadsorption mechanisms. ${ }^{10-12} \mathrm{~A}$ wide range of organisms have been employed for the bioadsorption of heavy metals from aqueous solutions. Multiple studies have demonstrated that dead cells may be more effective than living, mainly as the cell cannot actively reject (via efflux mechanisms) the potentially toxic metals or possibly through the increased availability of intracellular binding sites following cellular death and the associated degradation of internalised membrane structures..$^{32}$ Many factors are involved in the bioadsorption of metals onto algae, though biomass rich in organic ligands, containing functional groups such as carboxyl, hydroxyl, sulfates, phosphates and amines tend to be more effective. For microalgae such as Spirulina and Chlorella vulgaris the metal ions are attracted by the negative potential of the compounds in the cell wall. With increasing $\mathrm{pH}$, numerous sites are deprotonated that can then bind to metals in the solution. These include acetamide chitin, structural polysaccharides, phosphate and amino groups of nucleic acids, amino and carboxyl groups of proteins and hydroxyl groups of polysaccharides. ${ }^{11}$ Both Spirulina and Chlorella sp. contain a range of these compounds in the cell wall. As this is the case, temperature, a slightly acidic $\mathrm{pH}(4-6)$ and the presence of other metals are all important parameters in this process. ${ }^{12}$ For macroalgae the cell wall is key to the process. For brown algae, the cell wall contains predominantly three polymers; cellulose, alginic acid and small organic acid polymers such as mannuronic and guluronic acids, these are complexed with metals though also contain sulphated polysaccharides. ${ }^{33}$ It is the sulphated groups and alginic acid that are the predominant active groups. ${ }^{34}$ Green algae, such as Ulva, tend to have a high level of cellulose, as well as protein in the cell wall, and it is the proteins that play the fundamental role in bioadsorption. ${ }^{12}$ These proteins tend to be poor in sulphated groups such as methionine and cysteine, and high in aspartic acid, glycine and alanine. The complexation will be mainly through these acidic side chains. In this way most heavy metals have been demonstrated to be remediated as well as noble metals such as Pd and Pt. ${ }^{12}$

In this study, two microalgal feedstocks, Chlorella vulgaris (Chlorella) and Arthrospira platensis (Spirulina), and two macroalgal species, Ulva lactuca (Ulva) and Sargassum muticum (Sargassum) were selected. All four species have been demonstrated to have an affinity for heavy metals, and display good removal efficiencies, as well as being established feedstocks for the HTL process. ${ }^{12,29,35}$

First, the impact of the target metals on the HTL conversion of the four feedstocks was assessed at $340{ }^{\circ} \mathrm{C}$ by directly combining biomass with varying concentrations of the four metals of interest $\left(0,10,50,150 \mathrm{mmol} \mathrm{L}^{-1}\right)$.

Bio-crude yields and energy recovery for the four feedstocks, with no additional metals, were in line with previous reports, with the macroalgal species giving the expected lower crude yields than their microalgal counterparts (Fig. 1a). ${ }^{25,29}$ The direct addition of the metals to the biomass had little effect on the yield of bio-crude even at $150 \mathrm{mmol} \mathrm{L}^{-1}$, the upper range of what could effectively be bioadsorbed by the algae (Fig. 1a). Likewise, the elemental composition and higher heating values of the bio-crude did not change significantly on increasing the
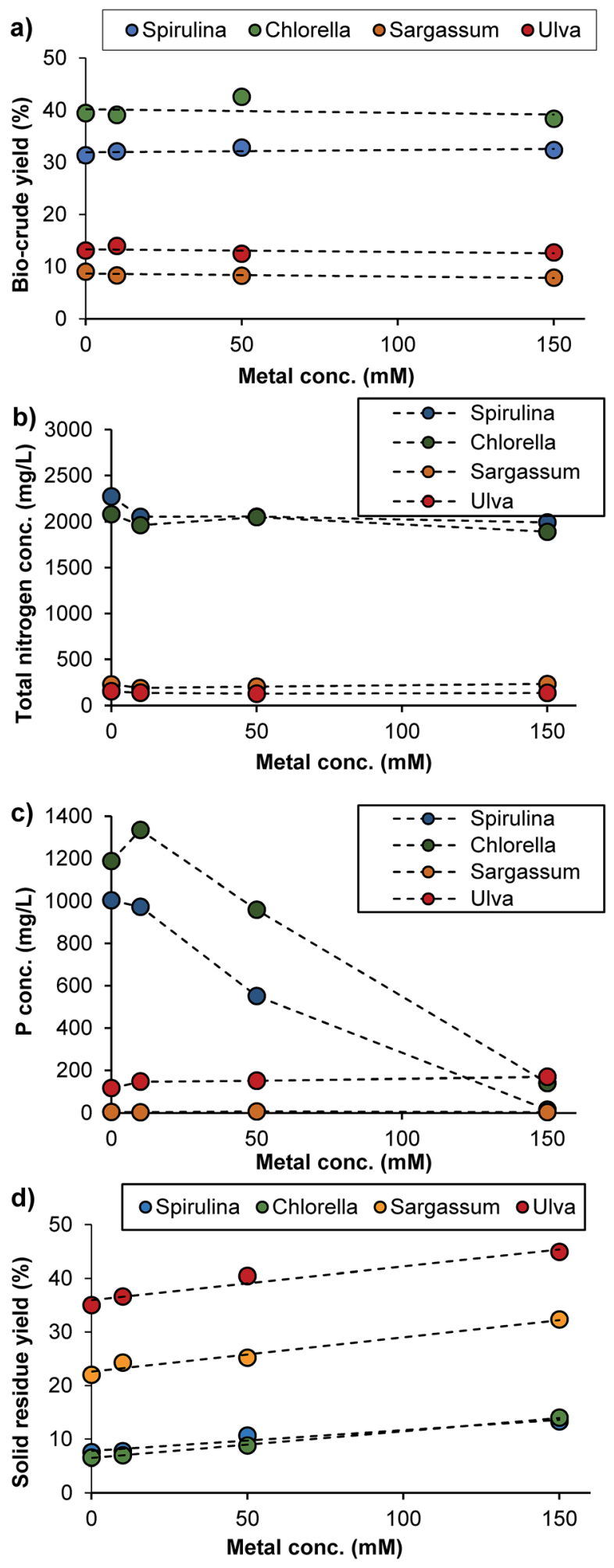

Fig. 1 Yields of (a) bio-crude as a function of initial dry weight of the biomass; (b) total nitrogen concentration in the aqueous phase; (c) $\mathrm{P}$ concentration in the aqueous phase; (d) solid char yield, for the hydrothermal liquefaction $\left(340^{\circ} \mathrm{C}, 12 \mathrm{~min}\right)$ of algal biomass with increasing metal (Zn(॥), Cd(॥), Ni(॥), Cu(॥)) loading.

metal concentration (see ESI†). Previously, we demonstrated that, while high loadings of $\mathrm{Mg}$ and Fe increased the bio-crude production from Spirulina, $\mathrm{Sn}$ and $\mathrm{Pb}$ had little effect. ${ }^{25}$ 
Analysis of the aqueous phase demonstrated that the total nitrogen concentration was highly dependent on feedstock, with high levels of $\mathrm{N}$ depositing in this phase for both microalgal species, though increasing the metal concentration did not have a strong effect (Fig. 1b). The P concentration in the aqueous phase derived from the macroalgal biomass was very low and not unduly affected by heavy metals (Fig. 1c). However, for both Spirulina and Chlorella, $\mathrm{P}$ concentration was elevated at low metal loading (1000-1200 $\mathrm{mg} \mathrm{L}^{-1}$ ); this then decreased on increasing metal loading. At $150 \mathrm{mmol} \mathrm{L}^{-1}$ of metals, $\mathrm{P}$ concentration was below $200 \mathrm{ppm}$ for both microalgal species, equivalent with their macroalgal counterparts.

On increasing metal concentration, the solid residue yield was increased substantially for all feedstocks examined, with a linear increase with increasing metal concentration (Fig. 1d). The elemental analysis of the solid residue demonstrated that on increasing metal loading, an increasing level of the target metals were deposited (Fig. 2). For the microalgal species, the solid residue was mainly composed of inorganics, oxygen, phosphorus and carbon. As more target metals were added to the system, the target metals recovered in the solid residue increased accordingly. Crucially, at a $150 \mathrm{mmol} \mathrm{L}^{-1}$ metal loading, approximately $0.2 \mathrm{mmol} \mathrm{L}^{-1}$ of $\mathrm{P}$ is repartitioned from the aqueous phase, which is then accounted for in the solid phase. This suggests that the elevated phosphates, typical of the two microalgae species tested, in the system react with the metals forming insoluble phosphate compounds depositing into the solid residue; however, other mechanisms are also likely to be playing a role, and metals are also likely to be present in the form of oxides and hydroxides.

For the macroalgal species, the solid residue contains substantially higher levels of carbon and hydrogen. This is presumably due to large asphaltene-type compounds, which are known to be produced from high-carbohydrate feedstocks. ${ }^{36} \mathrm{~A}$ similar deposition was observed with increasing metal loading, though with lower phosphorus levels in the starting feedstock, lower solid phase P levels were observed overall.

The percentage distribution of the target metals between the bio-crude, the aqueous phase and the solid residue of the system was assessed (Fig. 3). For the microalgal species, between $86.2 \%$ and $99.9 \%$ of the target metals were deposited in the solid residue at $10 \mathrm{mM}$ loadings, with the rest predominantly depositing in the bio-crude. This was reduced slightly at higher loadings, and whilst recovery was dependent on both the metal type and algal species, even at $150 \mathrm{mM}$ loadings, 90\% + metal recoveries were observed in many cases. Sargassum showed a similarly high metal recovery at low loadings, but at $150 \mathrm{mM} \mathrm{Zn}$ and $\mathrm{Cd}$ were not recovered easily, and rather deposited in the aqueous phase. Similarly, Ulva demonstrated very poor recoveries in the solid residue for $\mathrm{Ni}, \mathrm{Zn}$ and $\mathrm{Cd}$. These effects were highly dependent on the metal type, with excellent recoveries of $\mathrm{Cu}$ for all systems examined, possibly due to the preferential binding to phosphate within the system.

While the brown macroalgal species Sargassum works well in this system, retaining the predominant amount of metals in the solid phase, the green macroalgal species Ulva does not. Potentially this could be due to the mechanism of a) Chlorella

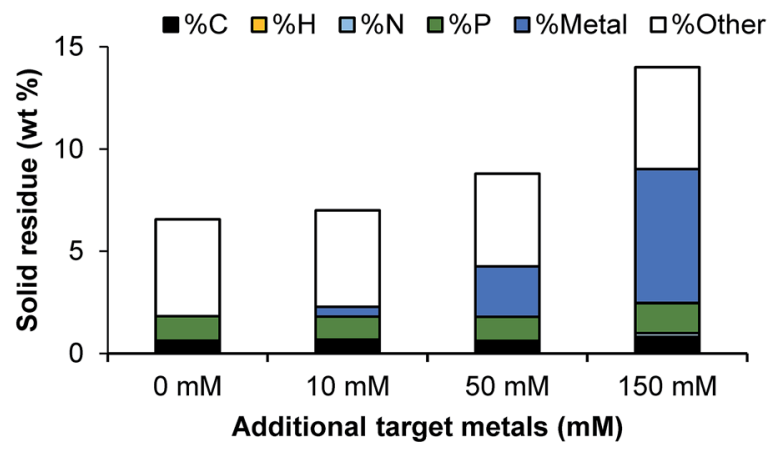

b) Spirulina

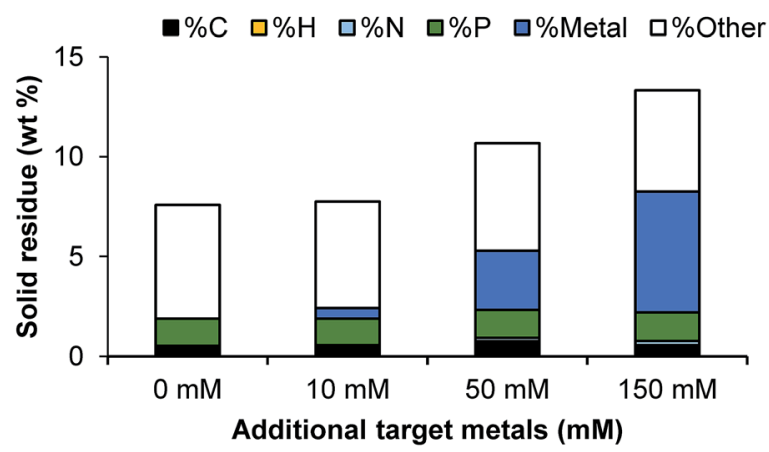

c) Sargassum

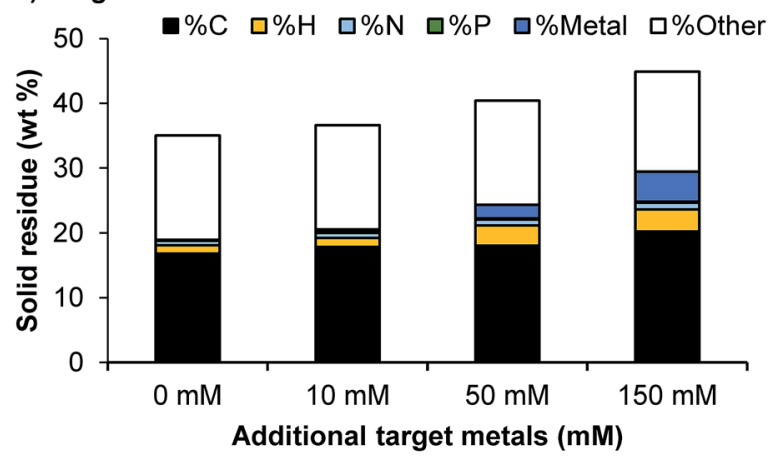

d) Ulva

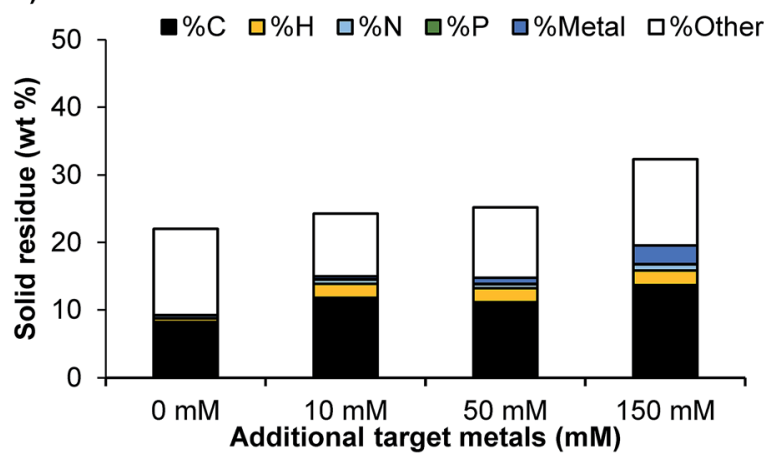

Fig. 2 Elemental composition of the solid residue (\% $\mathrm{w} / \mathrm{w})$ for carbon, hydrogen, nitrogen, phosphorus and the target metals (Ni, Zn, Cu, Cd) and others.

bioadsorption where the main metal binding is through functional groups on proteins. ${ }^{12}$ As proteins deposit mainly in the biocrude and aqueous phase this could aid the deposition of a proportion of these metals into these phases. Alternatively the 
a) $\mathrm{Ni} \quad \square$ Bio-crude $\square$ Aqueous phase $\square$ Solid residue

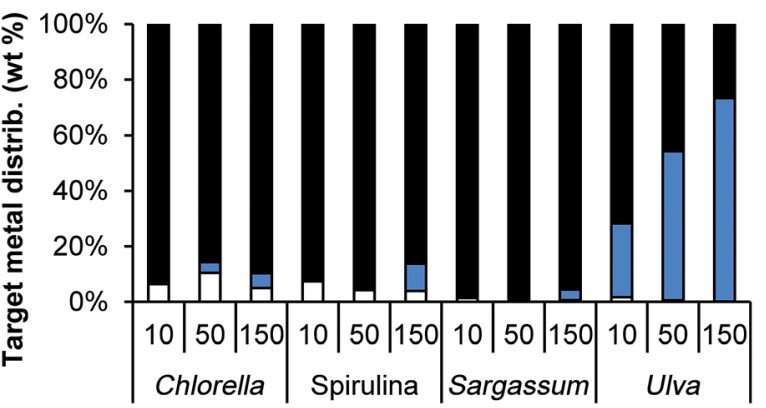

Additional metal conc. (mM)

b) $\mathrm{Cu} \quad \square$ Bio-crude $\square$ Aqueous phase $\square$ Solid residue

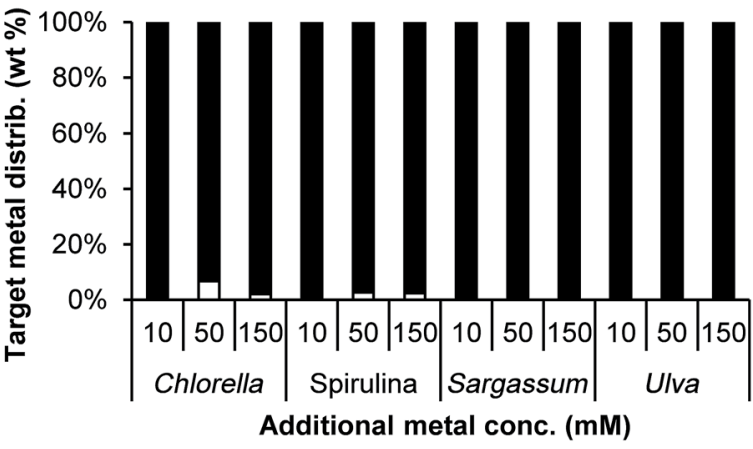

c) Zn $\quad$ Bio-crude $\square$ Aqueous phase $\square$ Solid residue

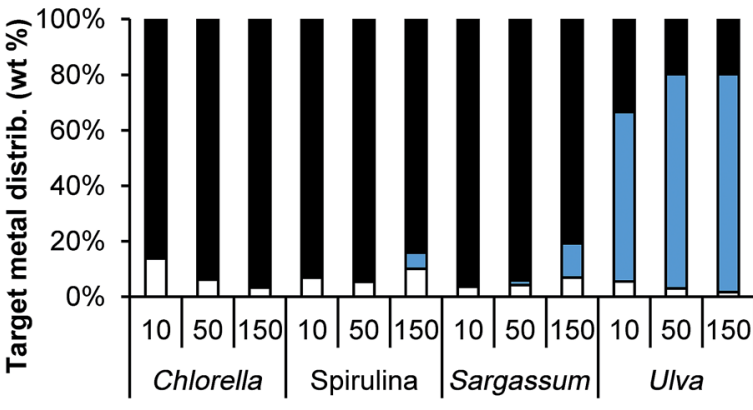

Additional metal conc. (mM)

d) Cd $\quad \square$ Bio-crude $\square$ Aqueous phase $\quad$ Solid residue

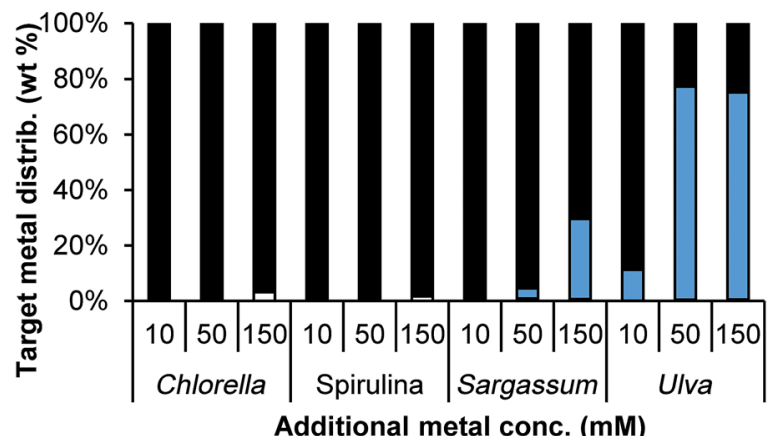

Fig. 3 Distribution of the target metals (wt\%) across the solid, aqueous and bio-crude phases.

main mechanism for brown alga tend to be through sulphated polysaccharides which would predominantly deposit in the solid.

The results clearly demonstrate that an algal-HTL system for remediation of heavy metals has promise, as even unrealistically high loadings of metals $(0.15 \mathrm{M})$ are partitioned into the solid phase on conversion of the algal biomass, crucially, with no impact on bio-crude production. To further investigate the suitability of the system as a remediation process, the metal salts were then exposed to the four algal species first, under relevant conditions for bioremediation, both individually and as a mixture, prior to their conversion with HTL (Fig. 4).

The metal-containing aqueous solutions $(10 \mathrm{mM})$ were stirred at room temperature with the dried algal biomass for 2 hours, in accordance with literature precedent. ${ }^{12,34}$ Metal uptake and bioadsorption efficiencies were determined via AAS (Fig. 4). For both microalgae, removal efficiency was very high for all metals (79-91\%), except for nickel (42-49\%), consistent with previous studies for these species. ${ }^{12}$ For the macroalgae, Sargassum was highly effective in all cases (73-89\%), while Ulva demonstrated the lowest bioabsorption efficiencies (28-61\%). Brown macroalgae contain large levels of alginates and sulphated polysaccharides (e.g. fucoidan) in the cell walls, which typically demonstrate higher metal uptake capacities. ${ }^{37}$ Contrastingly, the cell walls of green macroalgae are primarily composed of cellulose, with a minor protein fraction responsible for the metal bioabsorption. These results are consistent with previous findings demonstrating that green macroalgae show lower heavy metal uptake compared with brown macroalgae..$^{34,37}$

The experiments were then repeated for each alga with a solution containing all four metals $(2.5 \mathrm{mM}$ each, $10 \mathrm{mM}$ total). A similar trend in bioabsorption was observed. For both
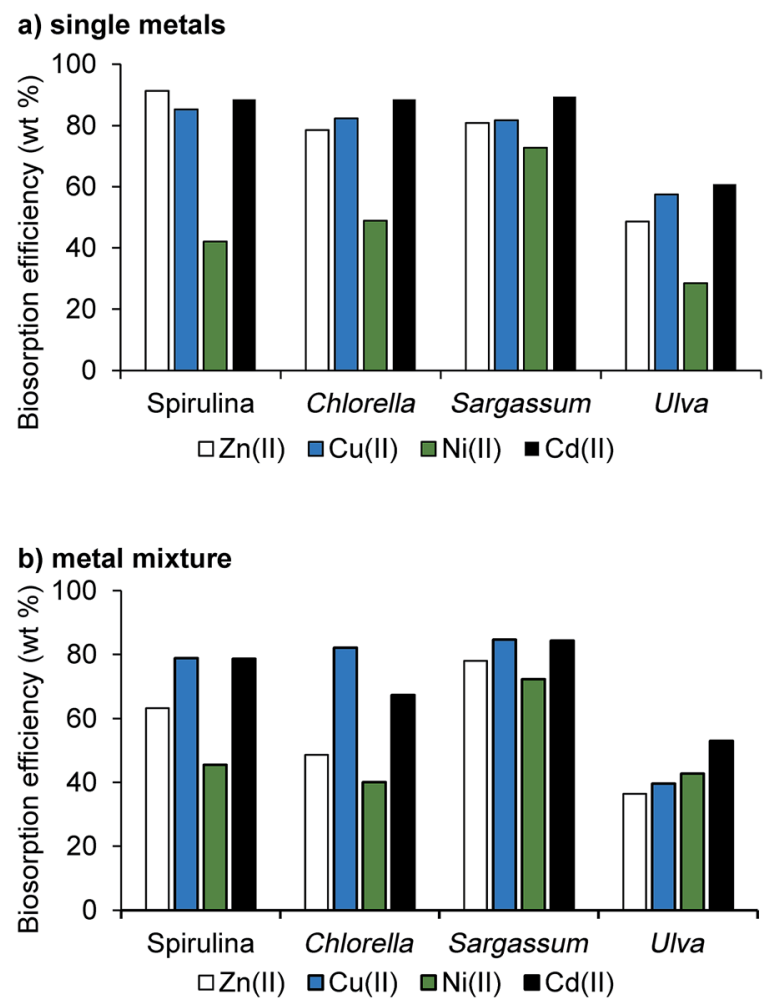

Fig. 4 Passive bioabsorption efficiency of the algal biomass over 2 hours at room temperature with (a) $10 \mathrm{mM}$ of each metal added singularly (b) $10 \mathrm{mM}$ total of all four metals. 
microalgae, the bioabsorption decreased significantly for zinc and slightly for cadmium. For macroalgae, while Sargassum did not show any change, for Ulva the bioabsorption increased for $\mathrm{Ni}$ and decreased for the other metals. Despite lower uptakes, algae were able to sequester a large fraction of the total metal content $(69 \%, 61 \%, 81 \%$ and $45 \%$ for Spirulina, Chlorella, Sargassum and Ulva, respectively).

After the bioabsorption phase, metal-containing algae were processed via HTL. Similarly to when the metal sulfates were added to the process, the bio-crude yields were not affected by bioabsorbed metals (Fig. 5a). For both Chlorella and Spirulina, the elemental composition of bio-crudes (see ESI $\dagger$ ) was similar to the control, though the elevated presence of zinc appeared to result in lower bio-crude oxygen, and subsequently higher HHV and energy recoveries than the control bio-crudes (Table 1). Microalgal feedstocks gave reasonably high energy recoveries in the bio-crude (42-50\% and $49-57 \%$ for Spirulina and Chlorella, respectively). Less carbon deposited in the bio-crudes for the macroalgal species, resulting in lower energy recoveries (17-28\% and $24-32 \%$ for Sargassum and Ulva, respectively). The effect of metals on the bio-crude was less pronounced for the macroalgae, with similar HHV, elemental composition and energy recoveries irrespective of the metal mixture used.

The aqueous phases obtained from the HTL process were analysed to assess the suitability for elemental recycle. To this end, total nitrogen, potassium and phosphorus concentration

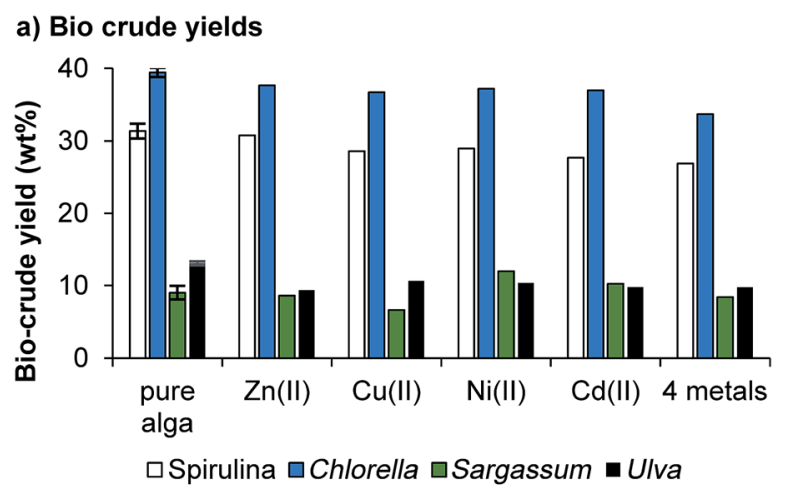

b) $N, P, K$ in aqueous phase

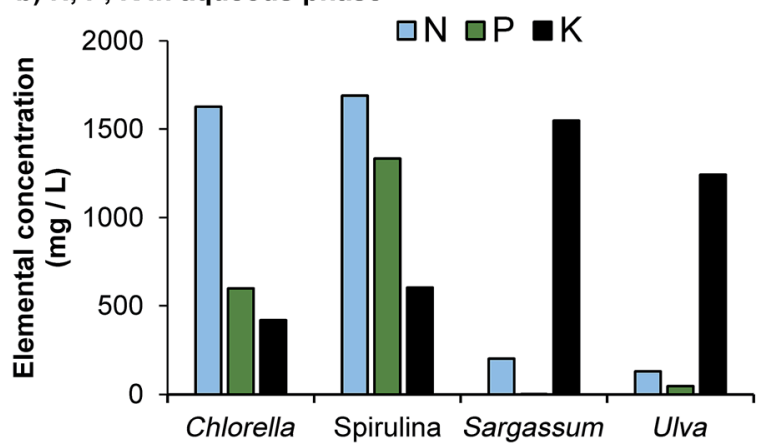

Fig. 5 Yields obtained from the $\mathrm{HTL}\left(340^{\circ} \mathrm{C}, 12 \mathrm{~min}\right)$ for the remediated algal biomass containing the heavy metal contamination where (a) bio-crude yields as weight percentage of the original biomass (b) phosphorus, total nitrogen and potassium concentration in the aqueous phase for the 4 metal mixtures.
Table $1 \mathrm{HHV}$ and energy recovery of the bio-crudes produced by the $\mathrm{HTL}\left(340{ }^{\circ} \mathrm{C}, 12 \mathrm{~min}\right)$ of the algal biomass with metal contamination

\begin{tabular}{|c|c|c|c|}
\hline \multirow[b]{2}{*}{ Algae } & \multirow[b]{2}{*}{ Metal type } & \multirow{2}{*}{$\frac{\mathrm{HHV}}{\mathrm{MJ} \mathrm{kg}^{-1}}$} & \multirow{2}{*}{$\frac{\text { Energy recovery }}{\%}$} \\
\hline & & & \\
\hline \multirow[t]{6}{*}{ Chlorella } & - & 33.5 & 56.7 \\
\hline & $\mathrm{Zn}(\mathrm{II})$ & 34.5 & 57.4 \\
\hline & $\mathrm{Cu}(\mathrm{II})$ & 33.0 & 53.6 \\
\hline & Ni(II) & 32.8 & 54.0 \\
\hline & $\mathrm{Cd}(\mathrm{II})$ & 34.0 & 55.5 \\
\hline & 4 Metals & 33.2 & 49.4 \\
\hline \multirow[t]{6}{*}{ Spirulina } & - & 32.6 & 46.8 \\
\hline & $\mathrm{Zn}(\mathrm{II})$ & 34.3 & 49.5 \\
\hline & $\mathrm{Cu}(\mathrm{II})$ & 31.2 & 41.9 \\
\hline & $\mathrm{Ni}(\mathrm{II})$ & 31.4 & 42.7 \\
\hline & Cd(II) & 33.2 & 43.2 \\
\hline & 4 Metals & 33.5 & 42.3 \\
\hline \multirow[t]{6}{*}{ Sargassum } & - & 33.4 & 18.7 \\
\hline & $\mathrm{Zn}(\mathrm{II})$ & 32.6 & 21.7 \\
\hline & $\mathrm{Cu}(\mathrm{II})$ & 33.9 & 17.3 \\
\hline & $\mathrm{Ni}(\mathrm{II})$ & 31.2 & 28.9 \\
\hline & Cd(II) & 31.6 & 25.1 \\
\hline & 4 Metals & 32.3 & 21.0 \\
\hline \multirow[t]{6}{*}{ Ulva } & - & 31.9 & 31.9 \\
\hline & $\mathrm{Zn}(\mathrm{II})$ & 33.1 & 23.6 \\
\hline & $\mathrm{Cu}(\mathrm{II})$ & 30.6 & 24.9 \\
\hline & $\mathrm{Ni}(\mathrm{II})$ & 29.7 & 23.5 \\
\hline & $\mathrm{Cd}(\mathrm{II})$ & 31.4 & 23.5 \\
\hline & 4 Metals & 32.6 & 24.3 \\
\hline
\end{tabular}

were analysed (Fig. 5b). On the conversion of the biomass used to remediate the metal mixture, elevated levels of $\mathrm{N}, \mathrm{P}$ and $\mathrm{K}$ were recovered in the aqueous phase for both the Spirulina and Chlorella species. This demonstrated that the elevated metals under these conditions did not remove substantial amounts of phosphate from the aqueous phase, and that these three key elements could be recycled to supplement further microalgal growth. Presumably due to the lower starting amount of $\mathrm{P}$ in the macroalgal biomass, little phosphate was recovered from the macroalgal species. However, whilst our primary focus is on the bioenergetic products from HTL, the exploitation of the aqueous phase as a fertiliser product is not without merit. Indeed, the extensive potassium partitioning to the aqueous phase is noteworthy following conversion of macroalgal biomass, and suggests that, should the fertiliser product become more predominant as a market driver, a dual microalgae-macroalgae process may prove amenable for deriving bespoke NPK blends for the agricultural market.

The solid residue products were the most strongly affected by the addition of metals (Fig. 6). For Spirulina and Chlorella, the solid residue generally changed composition with increasing metal content. While the target metals were a large part of this, the overall elemental composition also changed depending on metal. For example, for Spirulina, the addition of zinc led to a 3-fold increase in carbon and nitrogen content and a 7 -fold increase in hydrogen content. This suggests that the zinc is either catalysing or stabilising the formation of larger organic asphaltene-type molecules that are insoluble in the other phases. This effect is also observed with zinc and Chlorella, though it is 
less pronounced for the other metals. This corresponded with a slight decrease in the bio-crude yields. Phosphorus is also increased with the additional metal loadings across the samples.

\section{a) Chlorella}

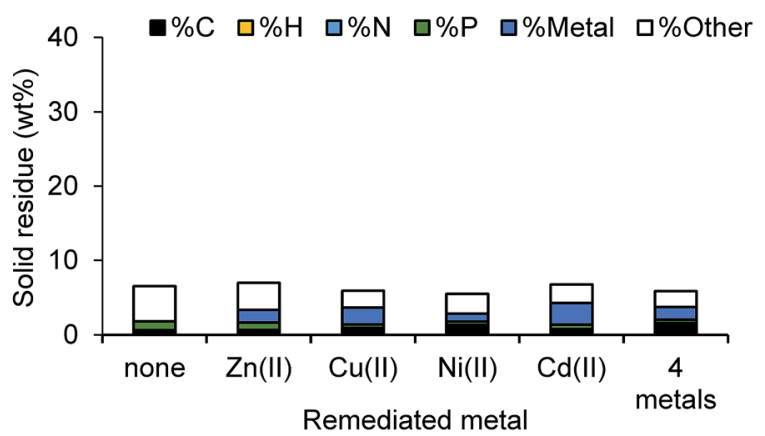

\section{b) Spirulina}

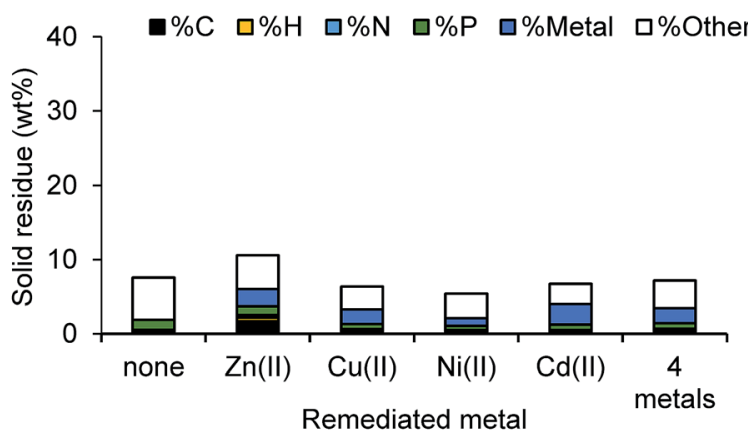

\section{c) Sargassum}

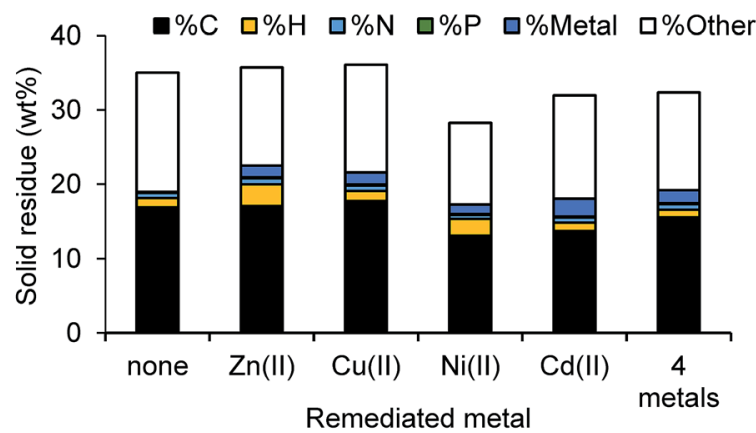

d) Ulva

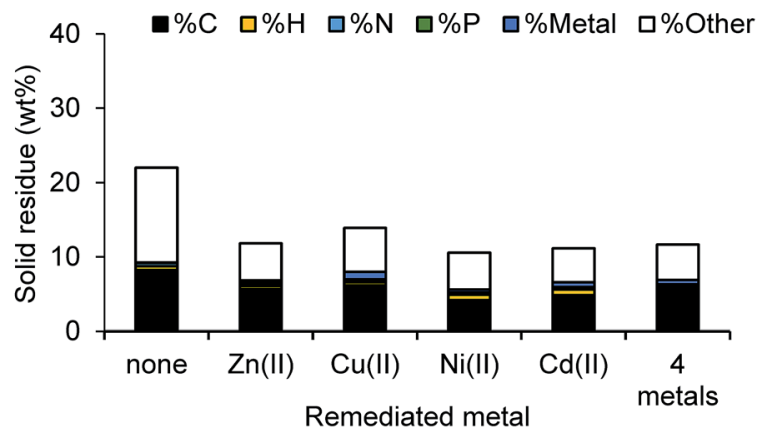

Fig. 6 Yield and elemental composition of the solid residues obtained from the $\mathrm{HTL}\left(340{ }^{\circ} \mathrm{C}, 12 \mathrm{~min}\right)$ of the metal contaminated algal biomass.
Carbon content of the solids derived from microalgae were relatively low (5-22 wt\%), whereas macroalgae lead to a high solid phase C content (37-49 wt\%), consistent with their higher carbohydrate content. ${ }^{38}$ The addition of metal seemed to reduce the carbon content in the solid residue for Ulva biomass in particular, potentially catalysing the decomposition of this phase into gas and soluble aqueous carbon species.

Both the Chlorella and Spirulina systems showed excellent target metal recovery, with over 95\% recovery for all the target metals in the solid residue for Spirulina, and between 90-99\% for Chlorella (Fig. 7a). This was improved on with the metal mixture. Similar to the model compounds, only trace amounts were deposited in the aqueous phase, ideal for using this for nutrient recycle. As with the model compounds, Cd(II) was deposited overwhelmingly in the solid phase, irrespective of the biomass or the loading of other metals involved. This suggests that it is not down to the relative stability of the sulfate over hydroxyl or phosphate species, but that the resulting cadmium species are extremely stable and insoluble in water. While Sargassum also demonstrated excellent recovery of the target metals to the solid phase, Ulva deposited a large proportion of the $\mathrm{Ni}, \mathrm{Zn}$ and $\mathrm{Cd}$ in to the aqueous phase upon HTL conversion.

a) single metals

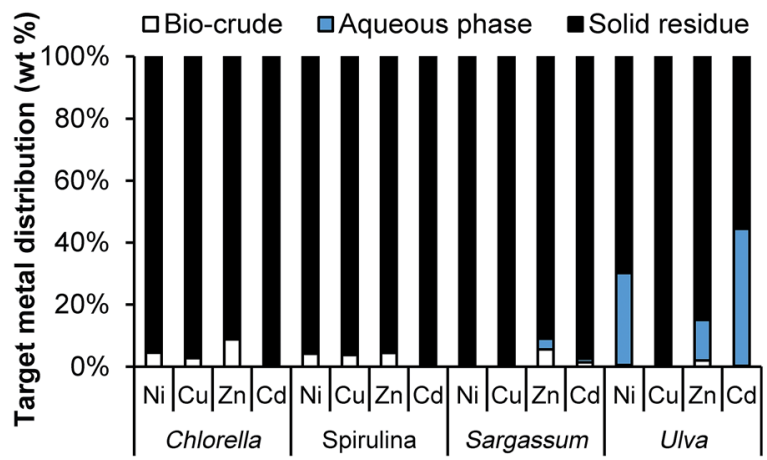

Additional target metals

b) metal mixture

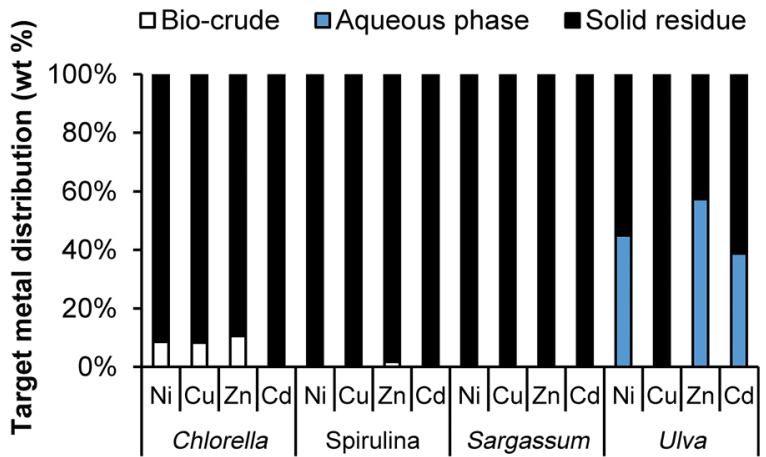

Additional target metals

Fig. 7 Distribution of the target metals (wt\%) across the solid, aqueous and bio-crude phases formed from the algal biomass used in the remediation where (a) is given for the single addition of metals and (b) is when all four metals were used simultaneously. 


\section{Conclusions}

Both microalgal and macroalgal biomass has been demonstrated previously to be an excellent method of remediating industrial waste water by removing heavy metal contaminants. In this study we demonstrated that this process can be effectively coupled to bioenergy production through the hydrothermal liquefaction of the biomass. While the algal processes generally work slower than chemical precipitation, by combining with liquefaction we have demonstrated a route to further higher value products, a clear advantage over chemical precipitation alone. Compared with standard HTL the bioabsorbed metals did not significantly affect the bio-crude yields, and similar energy recoveries were obtained as for just the starting algae with no additional metals. For the microalgal species, the target metals were almost entirely deposited in the solid residue, allowing ease of recovery. In addition, a significant proportion of $\mathrm{N}, \mathrm{P}$ and $\mathrm{K}$ deposited in the aqueous phase, which could be recycled for further algal or plant growth. This demonstrates that HTL is not only a highly promising method of converting algal biomass into fuels, but has significant advantages over other bioenergy production systems when coupled to algal bioremediation. Whilst microalgae outperformed macroalgae from a technical perspective, the upstream reduced production/harvesting costs associated with macroalgae represent a significant economic advantage, which may make up for the shortfall in downstream metal partitioning performance and bio-crude production. As always with such a generic and versatile technology, local solutions will need to be developed for local problems, and a full accompanying technoeconomic assessment would need to be developed to weigh the options effectively, though without doubt, our work shows that algae (no matter their size, shape or nature) show great promise for providing environmental remediation services in tandem with bioenergy production.

\section{Conflicts of interest}

There are no conflicts to declare.

\section{Acknowledgements}

The project has been partially supported by the EPSRC through the Centre for Doctoral Training in Sustainable Chemical Technologies (EP/L016354/1) and the Roddenberry Foundation. We also would like to thank Kevin Brigden and the team at the Greenpeace Research Laboratories, University of Exeter for the ICP-MS analysis. We also would like to thank Rosie and Archie Allen for collecting the seaweed biomass used in this study. The underlying research data can be accessed freely at https:// doi.org/10.15125/BATH-00539.

\section{Notes and references}

1 A. R. K. Gollakota, N. Kishore and S. Gu, Renewable Sustainable Energy Rev., 2018, 81, 1378-1392.
2 J. Wagner, R. Bransgrove, T. A. Beacham, M. J. Allen, K. Meixner, B. Drosg, V. P. Ting and C. J. Chuck, Bioresour. Technol., 2016, 207, 166-174.

3 X. Liu, B. Saydah, P. Eranki, L. M. Colosi, B. G. Mitchell, J. Rhodes and A. F. Clarens, Bioresour. Technol., 2013, 148, 163-171.

4 G. W. Roberts, M.-O. P. Fortier, B. S. Sturm and S. M. StaggWilliams, Energy Fuels, 2013, 27, 857-867.

5 Y. Zhou, L. Schideman, G. Yu and Y. Zhang, Energy Environ. Sci., 2013, 6, 3765-3779.

6 W.-T. Chen, Y. Zhang, J. Zhang, G. Yu, L. C. Schideman, P. Zhang and M. Minarick, Bioresour. Technol., 2014, 152, 130-139.

7 A. Mehrabadi, R. Craggs and M. M. Farid, Bioresour. Technol., 2017, 224, 255-264.

8 E. A. Couto, F. Pinto, F. Varela, A. Reis, P. Costa and M. L. Calijuri, Renewable Energy, 2018, 118, 644-653.

9 F. Fu and Q. Wang, J. Environ. Manage., 2011, 92, 407-418.

10 A. K. Zeraatkar, H. Ahmadzadeh, A. F. Talebi, N. R. Moheimani and M. P. McHenry, J. Environ. Manage., 2016, 181, 817-831.

11 K. S. Kumar, H.-U. Dahms, E.-J. Won, J.-S. Lee and K.-H. Shin, Ecotoxicol. Environ. Saf., 2015, 113, 329-352.

12 J. He and J. P. Chen, Bioresour. Technol., 2014, 160, 67-78.

13 C. M. Monteiro, P. M. Castro and F. X. Malcata, Biotechnol. Prog., 2012, 28, 299-311.

14 E. Malkoc and Y. Nuhoglu, Fresenius Environ. Bull., 2003, 12, 376-381.

15 S. K. Mehta and J. P. Gaur, Ecol. Eng., 2001, 18, 1-13.

16 I. Tüzün, G. Bayramoğlu, E. Yalçın, G. Başaran, G. Celik and M. Y. Arıca, J. Environ. Manage., 2005, 77, 85-92.

17 M. Vogel, A. Günther, A. Rossberg, B. Li, G. Bernhard and J. Raff, Sci. Total Environ., 2010, 409, 384-395.

18 C. Ortiz-Calederon, H. C. Silva and D. B. Vasquez, in Biomass volume estimation and valorisation for energy, ed. J. S.Tumuluru, InTech, 2017.

19 E. J. Kim, S. Park, H. J. Hong, Y. E. Choi and J. W. Yang, Bioresour. Technol., 2011, 102, 11155-11160.

20 A. Upadhyay, S. Mandotra, N. Kumar, N. Singh, L. Singh and U. Rai, Bioresour. Technol., 2016, 221, 430-437.

21 N. Arora, K. Gulati, A. Patel, P. A. Pruthi, K. M. Poluri and V. Pruthi, Algal Res., 2017, 24, 29-39.

22 Y. Liu, J.-j. Zhan and Y. Hong, Environ. Sci. Pollut. Res., 2017, 24, 26594-26604.

23 R. Richards and B. Mullins, Ecol. Modell., 2013, 249, 59-67. 24 J. Yang, J. Cao, G. Xing and H. Yuan, Bioresour. Technol., 2015, 175, 537-544.

25 S. Raikova, H. Smith-Baedorf, R. Bransgrove, O. Barlow, F. Santomauro, J. L. Wagner, M. J. Allen, C. G. Bryan, D. Sapsford and C. J. Chuck, Fuel Process. Technol., 2016, 142, 219-227.

26 J. Lu, J. Watson, J. Zeng, H. Li, Z. Zhu, M. Wang, Y. Zhang and Z. Liu, Process Saf. Environ. Prot., 2018, 115, 108-115.

27 C. Tian, Z. Liu, Y. Zhang, B. Li, W. Cao, H. Lu, N. Duan, L. Zhang and T. Zhang, Bioresour. Technol., 2015, 184, 336343. 
28 M. Von Sperling, Wastewater Characteristics, Treatment and Disposal, IWA Publishing, 2007.

29 S. Raikova, C. Le, T. Beacham, R. Jenkins, M. Allen and C. Chuck, Biomass Bioenergy, 2017, 107, 244-253.

30 L. S. Ferreira, M. S. Rodrigues, J. C. M. De Carvalho, A. Lodi, E. Finocchio, P. Perego and A. Converti, Chem. Eng. J., 2011, 173, 326-333.

31 S. A. Channiwala and P. P. Parikh, Fuel, 2002, 81, 1051-1063. 32 T. A. Davis, B. Volesky and A. Mucci, Water Res., 2003, 37, 4311-4330.
33 E. Romera, F. González, A. Ballester, M. L. Blázquez and J. A. Muñoz, Bioresour. Technol., 2007, 98, 3344-3353.

34 P. X. Sheng, Y.-P. Ting, J. P. Chen and L. Hong, J. Colloid Interface Sci., 2004, 275, 131-141.

35 D. L. Barreiro, W. Prins, F. Ronsse and W. Brilman, Biomass Bioenergy, 2013, 53, 113-127.

36 P. Biller and A. B. Ross, Biofuels, 2012, 3, 603-623.

37 E. Romera, F. González, A. Ballester, M. Blázquez and J. Munoz, Bioresour. Technol., 2007, 98, 3344-3353.

38 P. Biller and A. Ross, Bioresour. Technol., 2011, 102, 215-225. 